\title{
Blood Pressure Control and Associated Factors in the Elderly Hypertensive Patients: Follow-up Data from the Special Hypertensive Outpatient Clinic
}

\section{(1) Umut Kocabaş1, (1) Filiz Özerkan Çakan²}

1Başkent University Faculty of Medicine, Department of Cardiology, İstanbul, Turkey

${ }^{2}$ Ege University School of Medicine, Department of Cardiology, İzmir, Turkey

\begin{abstract}
Objectives: The primary purpose of this study is to determine demographic and clinical characteristics of hypertensive patients aged $\geq 65$ years. The secondary objective of the study is to determine blood pressure (BP) control rates and factors affecting BP control in hypertensive patients aged $\geq 65$ years.
\end{abstract}

Materials and Methods: Eighty-five hypertensive patients aged $\geq 65$ years [57 (67\%) women; mean age $70 \pm 5$ years] that were followed at our hypertension clinic between 2009 and 2015 were retrospectively investigated.

Results: The BP control rate was $28.2 \%$ at the first visit. After 5-year follow-up, the rate of achieving target BP levels was $71.8 \%$ for systolic, $85.9 \%$ for diastolic and $65.8 \%$ for both systolic and diastolic BP $(p<0.001)$. Logistic regression analysis revealed that high baseline systolic and diastolic BP and low education level were independent predictors of failure to achieve BP control.

Conclusion: The results of our study show that the BP control rates are low in geriatric hypertensive patients. On the other hand, close follow-up of these patients in specialized hypertension outpatient clinics increases treatment success and BP control rates. High baseline systolic and diastolic $\mathrm{BP}$ and low education level are independent predictors of failure to achieve BP control.

Keywords: Elderly patients, hypertension, treatment

Address for Correspondence: Umut Kocabaş, Başkent University Faculty of Medicine, Department of Cardiology, İstanbul, Turkey e-mail: umutkocabas@hotmail.com ORCID: orcid.org/0000-0001-6424-9399

Received: 18.07.2019 Accepted: 20.02.2020

Cite this article as: Kocabaş U, Özerkan Çakan F. Blood Pressure Control and Associated Factors in the Elderly Hypertensive Patients: Follow-up Data from the Special Hypertensive Outpatient Clinic. EJCM 2020;8(1):21-27.

DOI: 10.32596/ejcm.galenos.2020.07.041 


\section{Introduction}

Hypertension is one of the most important risk factors for the development of cardiovascular diseases ${ }^{(1)}$. The prevalence of hypertension increases with age, and the prevalence in patients aged $\geq 65$ years doubles the prevalence rate in ages $40-64$ years $^{(1,2)}$.

Although positive effects of blood pressure (BP) control on mortality and morbidity have been shown in many studies, BP control rate remains low in geriatric population. A meta-analysis of clinical trials has showed that the treatment of hypertension in older adults is as beneficial as that in younger adults ${ }^{(2,3)}$. Randomizedcontrolled trials have demonstrated that antihypertensive treatment in the elderly is associated with reduction in cardiovascular events ${ }^{(3)}$. In spite of improvements in the identification and treatment of hypertension, one-third to two-thirds of geriatric hypertensive patients do not achieve optimal BP values and continue to exist at risks for target organ damage ${ }^{(2)}$.

There have been very few studies conducted in Turkey regarding demographic and clinical characteristics of hypertensive patients in the geriatric population. In addition, there are very few studies in the literature which were conducted on the follow-up of these patients, evaluated follow-up results and investigated the factors affecting BP control. The primary objective of this study was to determine demographic and clinical characteristics of hypertensive patients aged $\geq 65$ years. The secondary objective of the study was to determine BP control rates at the end of the follow-up period and factors affecting BP control.

\section{Materials and Methods}

The study included 85 hypertensive patients aged $\geq 65$ years who were followed-up and treated for 5 years at the special hypertensive outpatient's clinic of our university hospital between September 2009 and September 2015. The archived medical records of the study patients were retrospectively reviewed, and all data were recorded on an electronic case report form. Patients who did not have at least one outpatient control data per year and patients with secondary hypertension were not included in the study.

Hypertension was defined as systolic $\mathrm{BP} \geq 140 \mathrm{mmHg}$ and/or diastolic BP $\geq 90 \mathrm{mmHg}$. Patients who were previously diagnosed with hypertension and/or who used antihypertensive medications were considered to have hypertension regardless of their BP levels at the first visit $^{(3)}$.

Electrocardiography (ECG) and echocardiography data of the patients in the study population were evaluated. Left ventricular hypertrophy (LVH) was evaluated on an ECG using Sokolow-Lyon index. The presence of atrial fibrillation or other types of arrhythmia and conduction abnormalities or ST segment changes were defined as pathological ECG findings ${ }^{(3)}$.

In echocardiographic examination, left ventricular mass index was calculated according to the guidelines of the American Society of Echocardiography using Devereux method. Left ventricular mass index levels $>95$ $\mathrm{g} / \mathrm{m}^{2}$ in women and $>115 \mathrm{~g} / \mathrm{m}^{2}$ in men were defined as $\mathrm{LVH}^{(4)}$.

History of coronary and/or peripheral artery disease, pathological ECG findings, the presence of LVH, high creatinine ( $\geq 1.3 \mathrm{mg} / \mathrm{dL}$ in $\mathrm{men}, \geq 1.2 \mathrm{mg} / \mathrm{dL}$ in women), microalbuminuria (excretion of $30-300 \mathrm{mg}$ albumin per day in 24-h urine sample) or overt proteinuria (excretion of $>300 \mathrm{mg}$ albumin per day in a 24-h urine sample), the presence of $\geq$ grade- 2 hypertensive retinopathy on fundoscopic examination, stroke and/or transient ischemic attack were defined as the indicators of target organ damage ${ }^{(3)}$.

The patients' education levels were also recorded as low education level (people who were primary school graduates or who had a lesser level of education) and high education level (people who were high school graduates or who had a higher level of education).

The Ethics Committee of Ege University approved the study (decision no and date: 18-4/26 and 03.04.2018). 


\section{Statistical Analysis}

Categorical variables were expressed as number and percent distribution and continuous variables were expressed as arithmetic mean and standard deviation. The chi-square test was used in the comparison of categorical variables in univariate analyses, the Student's t-test was used in parametric cases where continuous variables were compared with a dichotomous independent variable, and the Mann-Whitney U test was used in nonparametric cases. Paired t-test was used in dependent group comparisons. Variables that showed statistical significance $(p<0.05)$ in univariate analyses were further analysed using multivariate logistic regression analysis. In all hypothesis tests, maximum type-1 error was accepted as 0.05 . SPSS 15.0 statistics package programme was used in all analyses.

\section{Results}

Baseline demographic and clinical data of the study population recorded at the first visit are presented in Table 1.

The study included 85 hypertensive patients (57 females (67\%); mean age $70 \pm 5$ years) aged $\geq 65$ years. At the first visit, the BP control rate was $28.2 \%$. The systolic BP was $151 \pm 23 \mathrm{mmHg}$ and the diastolic BP was $92 \pm 13 \mathrm{mmHg}$. Fourteen (16.5\%) patients received monotherapy whereas $61(71.7 \%)$ patients received dual or triple combination therapy, and 10 (11.8\%) patients received $\geq 4$ antihypertensive drugs. The mean number of visits performed over a 5-year followup period was $13 \pm 3$. During these visits, change in medication and/or combination therapy was required because of inadequate antihypertensive effect in 41 patients (48.2\%) and because of adverse effects in 29 patients $(34.1 \%)$. Only 15 patients $(17.6 \%)$ were maintained on the same antihypertensive treatment for 5 years. The most common adverse effects because of antihypertensive medication use were orthostatic hypotension (16.4\%), cough (12.9\%), and constipation $(8.2 \%)$.
At the end of the 5-year follow-up period, the systolic BP decreased to $131 \pm 17 \mathrm{mmHg}(\mathrm{p}<0.001)$ and the diastolic BP decreased to $77 \pm 11 \mathrm{mmHg}(\mathrm{p}<0.001)$. The rates of achieving target BP level was $71.8 \%(\mathrm{p}<0.001)$ for systolic BP and $85.9 \%(p<0.001)$ for diastolic BP. The rate of achieving the target levels in both BP levels was $65.8 \%$ (Table 2).

Patient population was divided into two groups as patients achieving $\mathrm{BP}$ control $(\mathrm{n}=56,65.8 \%)$ and those who did not achieve BP control $(n=29,34.2 \%)$ at the end of 5-year follow-up period. Both groups had similar characteristics in terms of age, gender, and body mass index (BMI) levels. However, the rate of patients with low education level (people who were primary school graduates or who had a lesser level of education) was lower in patients with controlled BP than in those without BP control ( $23.2 \%$ vs $65.5 \%, \mathrm{p}=0.001$, respectively), and baseline systolic and diastolic BP values (145 \pm 23 $\mathrm{mmHg}$ vs $162 \pm 20, \mathrm{p}=0.001$ and $89 \pm 13 \mathrm{mmHg}$ vs $98 \pm 11$ $\mathrm{mmHg}, \mathrm{p}=0.001$, respectively) were significantly higher in patients who did not achieve BP control (Table 3).

Multivariate logistic regression model was used to determine the predictors of achieving BP control at the end of 5-year follow-up period. Age, number of visits, education level, baseline systolic and diastolic BP levels were included in this model. As a result of logistic regression analysis, it was detected that high baseline systolic BP [odds ratio $(\mathrm{OR})=1.28,95 \%$ confidence interval $(\mathrm{CI})=1.004-1.53, \mathrm{p}=0.02]$, high baseline diastolic BP $(\mathrm{OR}=1.48,95 \% \mathrm{CI}=1.005-1.93, \mathrm{p}=0.02)$ and lower education level $(\mathrm{OR}=5.64,95 \% \mathrm{CI}=1.93-16.51, \mathrm{p}=0.002)$ were found to be independent predictors of failure to achieve BP control (Table 4).

\section{Discussion}

The results of our study show that the BP control rates are low in geriatric hypertensive patients. On the other hand, close follow-up of these patients in specialized hypertension outpatient clinics increases treatment success and BP control rates. 
Table 1. Demographic and clinical data of patients at the first visit

\begin{tabular}{|c|c|}
\hline Variable & $(n=85)$ \\
\hline Age (years) & $70 \pm 5(65-75)$ \\
\hline Gender (female) (n/\%) & $57(67.1)$ \\
\hline Body mass index $\left(\mathrm{kg} / \mathrm{m}^{2}\right)$ & $28.7 \pm 3.7$ \\
\hline Education level (low education level) (n/\%) & $32(37.6)$ \\
\hline Duration of hypertension (years) & $13 \pm 7(5-35)$ \\
\hline Number of visits & $13 \pm 3(7-25)$ \\
\hline $\begin{array}{l}\text { Regular usage of antihypertensive medication } \\
(n / \%)\end{array}$ & $75(88.2)$ \\
\hline \multicolumn{2}{|l|}{ Antihypertensive therapy ( $\mathrm{n} / \%)$} \\
\hline Monotherapy & $14(16.5)$ \\
\hline 2 anti-hypertensive drugs & $30(35.3)$ \\
\hline 3 anti-hypertensive drugs & $31(36.4)$ \\
\hline$\geq 4$ anti-hypertensive drugs & $10(11.8)$ \\
\hline \multicolumn{2}{|l|}{ Hypertension stages (n/\%) } \\
\hline Normal or pre-hypertension & $24(28.2)$ \\
\hline Stage 1 hypertension & $25(29.4)$ \\
\hline Stage 2 hypertension & $21(24.7)$ \\
\hline Stage 3 hypertension & $13(15.3)$ \\
\hline Isolated systolic hypertension & $2(2.4)$ \\
\hline Diabetes Mellitus (n/\%) & $10(11.8)$ \\
\hline Hyperlipidemia (n/\%) & $44(51.8)$ \\
\hline Smoking (n/\%) & $21(24.7)$ \\
\hline \multicolumn{2}{|l|}{ BMI classification ( $n / \%)$} \\
\hline Normal & $11(12.9)$ \\
\hline Overweight & $42(49.4)$ \\
\hline Class 1 obesity & $24(28.2)$ \\
\hline Class 2 obesity & $8(9.4)$ \\
\hline $\begin{array}{l}\text { Presence of systemic hypertension in the first-degree } \\
\text { relatives }(n / \%)\end{array}$ & $55(64.7)$ \\
\hline \multicolumn{2}{|l|}{ Target organ damage $(\mathrm{n} / \%)$} \\
\hline Coronary artery disease & $10(11.8)$ \\
\hline Pathological ECG finding & $28(32.9)$ \\
\hline Left ventricular hypertrophy $\left(\mathrm{g} / \mathrm{m}^{2}\right)$ & $27(31.8)$ \\
\hline High creatinine level & $14(16.4)$ \\
\hline Microalbuminuria & $20(23.5)$ \\
\hline Overt proteinuria & $4(4.7)$ \\
\hline Stroke/TIA & $7(8.2)$ \\
\hline Hypertensive retinopathy ( $\geq$ grade 2 ) & $28(32.9)$ \\
\hline
\end{tabular}

Table 1. Continued

\begin{tabular}{l|c|}
$\begin{array}{l}\text { Variable } \\
\text { Number of target organ damage (n/\%) }\end{array}$ & $(\mathbf{n}=\mathbf{8 5})$ \\
\hline None & $26(30.6)$ \\
\hline $\begin{array}{l}\text { target organ damage } \\
2 \text { target organ damage }\end{array}$ & $30(35.3)$ \\
\hline 3 target organ damage & $22(25.9)$ \\
\hline $\begin{array}{l}\text { ECG: Electrocardiography, TIA: Transient ischemic attack, SD: Standard } \\
\text { deviation, BMI: Body mass index } \\
\text { Data are given as mean } \pm \text { SD with total range, number of patients }(n) \text { and } \\
\text { percentages (\%) }\end{array}$ & $7(8.2)$ \\
\hline
\end{tabular}

The prevalence of hypertension is increasing with ageing population in the world. Hypertension has a significant importance as a cardiovascular risk factor in the geriatric population, and control of BP decreases cardiovascular mortality and morbidity rates ${ }^{(3)}$. However, observational and epidemiological studies show that BP control rates are not at the desired levels especially in the geriatric population $^{(2,3)}$.

All patients included in our study were those who had been previously diagnosed with hypertension and who were using hypertensive medications. Although 88\% of the patients stated at the first visit that they regularly used their hypertensive medication, BP control rates were quite low at the same visit. In the Patent study, which was performed to determine the prevalence of hypertension in Turkey, it was detected that $59 \%$ of hypertensive people were not aware of their high BP, only $31 \%$ of people that developed awareness were receiving treatment, BP control rate was $20 \%$ in those receiving treatment, and $\mathrm{BP}$ control rate was only $8.1 \%$ in the whole patient group ${ }^{(5)}$. In other studies conducted in Turkey, BP control rates among hypertensive people who were receiving medical therapy were reported to be ranging between $36 \%$ and $38 \%{ }^{(6,7)}$. In the studies conducted on geriatric population group, this rate varies between $14 \%$ and $36 \%{ }^{(6,8-10)}$. BP control rates in our study were $28.2 \%$ (24 of 85 patients) for systolic BP and $31.8 \%$ (27 of 85 patients) for diastolic BP, which are similar to that in other observational studies ${ }^{(6-8)}$.

There was a significant decrease in systolic and diastolic BP levels of the whole patient group at the end 
of the 5-year follow-up period. Systolic BP control rate increased to $71 \%$ from $28 \%$ and diastolic BP control rate increased to $85 \%$ from $31 \%$. The fact that the BP control rates recorded at the first visit is low despite the high rate of patients using combination therapies and number of patients who stated they used medications regularly shows that treatment success is not at the desired level. The results of our study show that diagnosing hypertension and prescribing antihypertensive treatment is not sufficient to control BP. Close monitoring of patients who start treatment, frequent BP checks, self-monitoring and dose titration of the antihypertensive medication and/or choice of combination therapies according to the measured BP levels are of high importance.

The results of our study show that there is evidence of at least one or more target organ damage in a significant portion (69.4\%, 59 of 85 patients) of geriatric hypertensive patients. In a study of 1163 patients with resistant hypertension aged $\geq 80$ years, Liang et al. ${ }^{(11)}$ reported a

Table 2. Comparison of baseline and 5-year follow-up data

\begin{tabular}{|c|c|c|c|}
\hline & Baseline & $5^{\text {th }}$ year & $\mathbf{p}$ \\
\hline Body mass index $\left(\mathrm{kg} / \mathrm{m}^{2}\right)$ & $28.7 \pm 3.7$ & $28.9 \pm 3.6$ & 0.17 \\
\hline $\begin{array}{l}\text { Average systolic blood } \\
\text { pressure }(\mathrm{mmHg})\end{array}$ & $151 \pm 23$ & $131 \pm 17$ & $<0.001$ \\
\hline $\begin{array}{l}\text { Average diastolic blood } \\
\text { pressure }(\mathrm{mmHg})\end{array}$ & $92 \pm 13$ & $77 \pm 11$ & $<0.001$ \\
\hline $\begin{array}{l}\text { Systolic blood pressure }(<140 \\
\mathrm{mmHg})(\mathrm{n} / \%)\end{array}$ & $24(28.2)$ & $61(71.8)$ & $<0.001$ \\
\hline $\begin{array}{l}\text { Diastolic blood pressure }(<90 \\
\mathrm{mmHg})(\mathrm{n} / \%)\end{array}$ & $27(31.8)$ & $73(85.9)$ & $<0.001$ \\
\hline Heart rate (bpm) & $79 \pm 8$ & $82 \pm 12$ & 0.12 \\
\hline Total cholesterol (mg/dL) & $230 \pm 39$ & $202 \pm 34$ & $<0.001$ \\
\hline Triglyceride (mg/dL) & $147 \pm 61$ & $145 \pm 65$ & 0.66 \\
\hline HDL-cholesterol (mg/dL) & $52 \pm 13$ & $51 \pm 11$ & 0.28 \\
\hline LDL-cholesterol (mg/dL) & $144 \pm 31$ & $124 \pm 28$ & $<0.001$ \\
\hline Fasting blood sugar (mg/dL) & $106 \pm 20$ & $105 \pm 19$ & 0.61 \\
\hline Creatinine $(\mathrm{mg} / \mathrm{dL})$ & $1.04 \pm 0.2$ & $1.01 \pm 0.2$ & 0.25 \\
\hline Potassium (mmol/L) & $4.3 \pm 0.4$ & $4.5 \pm 0.4$ & 0.02 \\
\hline Sodium (mmol/L) & $141 \pm 3$ & $140 \pm 2$ & 0.16 \\
\hline Hematocrit (\%) & $45 \pm 4$ & $44 \pm 4$ & 0.54 \\
\hline
\end{tabular}

HDL: High-density lipoprotein, LDL: Low-density lipoprotein, SD: Standard deviation

Data are given as mean $\pm S D$, number of patients ( $n$ ) and percentages (\%).

$p$ value $<0.05$ was considered statistically significant prevalence rate of $75 \%$ for hypertensive retinopathy and a rate of $71 \%$ for $\mathrm{LVH}$. On the other hand, in a study

Table 3. Comparison of demographic and clinical characteristics of patients with and without controlled blood pressure at the end of 5-year follow-up period

\begin{tabular}{|c|c|c|c|}
\hline & $\begin{array}{l}\text { Patients } \\
\text { with } \\
\text { controlled } \\
\text { blood } \\
\text { pressure } \\
(n=56)\end{array}$ & $\begin{array}{l}\text { Patients } \\
\text { without } \\
\text { controlled } \\
\text { blood } \\
\text { pressure } \\
(n=29)\end{array}$ & $\mathbf{p}$ \\
\hline Age (years) & $70 \pm 5$ & $70 \pm 6$ & 0.90 \\
\hline Gender (female) (n/\%) & $35(62.5)$ & $22(75.9)$ & 0.31 \\
\hline Body mass index $\left(\mathrm{kg} / \mathrm{m}^{2}\right)$ & $28.5 \pm 3.4$ & $29.7 \pm 3.8$ & 0.16 \\
\hline Low education level (n/\%) & $13(23.2)$ & $19(65.5)$ & 0.001 \\
\hline $\begin{array}{l}\text { Duration of hypertension } \\
\text { (years) }\end{array}$ & $12 \pm 6$ & $15 \pm 9$ & 0.10 \\
\hline Number of visits & $13 \pm 2$ & $15 \pm 5$ & 0.01 \\
\hline Diabetes Mellitus (n/\%) & $7(12.5)$ & $3(10.3)$ & 0.77 \\
\hline Hyperlipidemia (n/\%) & $29(51.8)$ & $15(51.7)$ & 0.99 \\
\hline Smoking (n/\%) & $18(32.1)$ & $3(10.3)$ & 0.05 \\
\hline $\begin{array}{l}\text { Presence of systemic } \\
\text { hypertension in the first- } \\
\text { degree relatives }(n / \%)\end{array}$ & $36(64.3)$ & $19(65.5)$ & 0.91 \\
\hline $\begin{array}{l}\text { Baseline systolic blood } \\
\text { pressure }(\mathrm{mmHg})\end{array}$ & $145 \pm 23$ & $162 \pm 20$ & 0.001 \\
\hline $\begin{array}{l}\text { Baseline diastolic blood } \\
\text { pressure }(\mathrm{mmHg})\end{array}$ & $89 \pm 13$ & $98 \pm 11$ & 0.001 \\
\hline Baseline heart rate (bpm) & $79 \pm 7$ & $78 \pm 9$ & 0.50 \\
\hline Total cholesterol (mg/dL) & $201 \pm 32$ & $204 \pm 39$ & 0.73 \\
\hline Triglyceride (mg/dL) & $150 \pm 74$ & $135 \pm 42$ & 0.33 \\
\hline HDL-cholesterol (mg/dL) & $51 \pm 11$ & $51 \pm 12$ & 0.88 \\
\hline LDL-cholesterol (mg/dL) & $121 \pm 30$ & $129 \pm 26$ & 0.25 \\
\hline $\begin{array}{l}\text { Fasting blood sugar } \\
\text { (mg/dL) }\end{array}$ & $102 \pm 15$ & $110 \pm 25$ & 0.09 \\
\hline Creatinine $(\mathrm{mg} / \mathrm{dL})$ & $1.04 \pm 0.3$ & $0.95 \pm 0.2$ & 0.03 \\
\hline $\begin{array}{l}\text { Presence of target organ } \\
\text { damage }(n / \%)\end{array}$ & $36(64.3)$ & $23(79.3)$ & 0.23 \\
\hline $\begin{array}{l}\text { Pathological ECG finding } \\
(\mathrm{n} / \%)\end{array}$ & $6(10.7)$ & $8(27.6)$ & 0.06 \\
\hline $\begin{array}{l}\text { Left ventricular mass index } \\
\left(\mathrm{g} / \mathrm{m}^{2}\right)\end{array}$ & $94 \pm 16$ & $110 \pm 34$ & 0.07 \\
\hline $\begin{array}{l}\text { Hypertensive retinopathy } \\
{[(\geq \text { grade } 2)(n / \%)]}\end{array}$ & 19 (33.9) & $9(31)$ & 0.78 \\
\hline \multicolumn{4}{|c|}{$\begin{array}{l}\text { ECG: Electrocardiography, HDL: High-density lipoprotein, LDL: Low- } \\
\text { density lipoprotein, SD: Standard deviation }\end{array}$} \\
\hline
\end{tabular}


conducted by Muxfeldt et al. ${ }^{(12)}$ on outpatients admitted to a university hospital, the prevalence of LVH was reported to be $33 \%$ and the prevalence of hypertensive retinopathy was reported to be $22 \%$. Similarly, in our study, the most frequently encountered target organ damage indicators were $\geq$ grade 2 hypertensive retinopathy $(32.9 \%)$ and LVH (31.8\%). In the Patent study, high serum creatinine was detected in $2.7 \%$ of the patients, microalbuminuria was detected in $27.4 \%$ of the patients, and overt proteinuria was detected in $3.7 \%$ of the patients ${ }^{(5)}$. In our study, the prevalence of microalbuminuria was $23.5 \%$ and the prevalence of overt proteinuria was $4.7 \%$. On the other hand, the rate of patients with high creatinine levels in our study was $16.4 \%$, and this was higher than that reported in the Patent study. The reason for this may be that the patient population in our study was older and the number of patients with high creatinine may be higher related to this.

In the studies evaluating the factors affecting BP control in geriatric population, it was detected that Diabetes Mellitus (DM), high BMI and obesity, advanced age, family history of hypertension and active smoking were related to failure to achieve BP control ${ }^{(8,11)}$. On the other hand, in a study conducted by Lima et al. ${ }^{(13)}$ on geriatric patients, there was no relationship between BP control and DM or BMI, whereas it was seen that high baseline BP level in the outpatient clinics and during 24-h $\mathrm{BP}$ monitoring was negatively correlated with BP control. In our study, there was no difference between the groups in terms of age, gender, BMI, DM and hyperlipidemia

Table 4. Independent predictors of failure to achieve blood pressure control: logistic regression model

\begin{tabular}{|l|l|l|l|}
\hline Variable & $\begin{array}{l}\text { Odds } \\
\text { ratio }\end{array}$ & $\begin{array}{l}95 \% \\
\text { Confidence } \\
\text { interval }\end{array}$ & $\mathbf{p}$ \\
\hline Age & 0.98 & $0.90-1.08$ & 0.80 \\
\hline Number of visits & 1.13 & $0.98-1.30$ & 0.07 \\
\hline Low educational level & 5.64 & $1.93-16.51$ & 0.002 \\
\hline Baseline systolic blood pressure & 1.28 & $1.004-1.53$ & 0.02 \\
\hline Baseline diastolic blood pressure & 1.48 & $1.005-1.93$ & 0.02 \\
\hline$p$ value <0.05 was considered statistically significant & \\
\hline
\end{tabular}

frequency. In our study, systolic and diastolic BP levels measured at the first visit were significantly higher in patients who did not achieve BP control and they required more frequent outpatient control visits than patients that achieved BP control. In another study conducted by Erem et al. ${ }^{(14)}$, an inverse relationship was detected between low education level and the prevalence of hypertension. According to the results of their study, the prevalence of hypertension was as high as $74 \%$ in people with a low education level, whereas this rate was $26 \%$ in university graduates. In a study conducted by Yang et al. ${ }^{(8)}$, the rate of patients that achieved BP control was $49 \%$ in patients with a high education level and this rate was 33\% in people with a low education level. In a multi-center study involving 17014 geriatric hypertensive patients, an inverse relationship was found between low education level and BP control ${ }^{(15)}$. In our study, similarly, a direct relationship was found between low education level and failure to achieve BP control. In multivariate logistic regression analysis, it has been detected that low education level and high baseline systolic and diastolic BP are independent predictors of failure to achieve BP control.

\section{Study Limitations}

The present study has some important limitations. Study population was formed by a limited number of patients and the study was conducted in a single center. BP measurements of the patients were obtained during the outpatient examination. Ambulatory BP measurement was not performed in all patients. Thus, white-coat hypertension or masked hypertension could not be diagnosed. Because the study data were collected retrospectively, lifestyle and lifestyle changes of the patients (physical exercise, sedentary life, nutritional habits, salt and alcohol consumption, stress) could not be evaluated.

\section{Conclusion}

The results of our study revealed demographic and clinical characteristics of hypertensive patients aged $\geq 65$ years. In addition, BP control rates and the factors affecting BP control were evaluated at the end of 5-year 
follow-up period at a specialized hypertension outpatient clinics. It can be seen that diagnosing geriatric patients with hypertension and starting antihypertensive treatment is not sufficient to achieve BP control. BP control is not achieved in a significant portion of patients despite the use of antihypertensive medications. However, close monitoring of these patients in specialized hypertension outpatient clinics increases the treatment success and BP control rates. High baseline systolic and diastolic BP and low education level are independent predictors of failure to achieve BP control.

\section{Ethics}

Ethics Committee Approval: The Ethics Committee of Ege University approved the study (Decision no and date: $18-4 / 26$ and 03.04.2018).

Informed Consent: Informed consent was obtained from the patients.

Peer-review: Externally peer-reviewed.

\section{Authorship Contributions}

Surgical and Medical Practices: U.K., F.Ö.Ç., Concept: U.K., F.Ö.Ç., Design: U.K., F.Ö.Ç., Data Collection or Processing: U.K., F.Ö.Ç., Analysis or Interpretation: U.K., F.Ö.Ç., Literature Search: U.K., F.Ö.Ç., Writing: U.K., F.Ö.Ç.

Conflict of Interest: No conflict of interest was declared by the authors.

Financial Disclosure: The authors declared that this study received no financial support.

\section{References}

1. Wang W, Lee ET, Fabsitz RR, et al. A longitudinal study of hypertension risk factors and their relation to cardiovascular disease: the Strong Heart Study. Hypertension 2006;47:403-9.

2. Chobanian AV. Clinical practice. Isolated systolic hypertension in the elderly. N Engl J Med 2007;357:789-96.
3. Mancia G, Fagard R, Narkiewicz K, et al. 2013 ESH/ESC guidelines for the management of arterial hypertension: the Task Force for the Management of Arterial Hypertension of the European Society of Hypertension (ESH) and of the European Society of Cardiology (ESC). Eur Heart J 2013;34:2159219.

4. Lang RM, Badano LP, Mor-Avi V, et al. Recommendations for cardiac chamber quantification by echocardiography in adults: an update from the American Society of Echocardiography and the European Association of Cardiovascular Imaging. Eur Heart J Cardiovasc Imaging 2015;16:233-70.

5. Altun B, Arici M, Nergizoğlu G, et al; Turkish Society of Hypertension and Renal Diseases. Prevalence, awareness, treatment and control of hypertension in Turkey (the PatenT study) in 2003. J Hypertens $2005 ; 23: 1817-23$

6. Altıparmak S, Karadeniz G, Altıparmak O, Ataseven M, Sahin R. Hypertension prevalance among elderly people: A sample from Manisa. Turk Geriatri Derg 2006;9:197-201.

7. Altun B, Süleymanlar G, Utaş C, et al. Prevalence, awareness, treatment and control of hypertension in adults with chronic kidney disease in Turkey: results from the CREDIT study. Kidney Blood Press Res 2012;36:36-46.

8. Yang L, Xu X, Yan J, et al. Analysis on associated factors of uncontrolled hypertension among elderly hypertensive patients in Southern China: a community-based, cross-sectional survey. BMC Public Health 2014;14:903.

9. Yadav G, Chaturvedi S, Grover VL. Prevalence, awareness, treatment and control of hypertension among the elderly in a resettlement colony of Delhi. Indian Heart J 2008;60:313-7.

10. Halil M, Cankurtaran M, Ulger Z, et al. Awareness and control of hypertension among the elderly in a university hospital. Clin Exp Hypertens 2006;28:683-93

11. Liang ZR, Gao LG, Cao J, Cui H, Fan L, Gao DW. Clinical characteristics, target organ damage and associate risk factors of resistant hypertension determined by ambulatory blood pressure monitoring in patients aged $\geq 80$ years. J Geriatr Cardiol 2017;14:308-14.

12. Muxfeldt ES, Nogueira Ada R, Salles GF, Bloch KV. Demographic and clinical characteristics of hypertensive patients in the internal medicine outpatient clinic of a university hospital in Rio de Janeiro. Sao Paulo Med J 2004;122:87-93

13. Lima NK, Moriguti JC, Ferriolli E. Uncontrolled hypertension in older patients: markers and associated factors to masked and white-coat effect. J Geriatr Cardiol 2016;13:672-8.

14. Erem C, Hacihasanoglu A, Kocak M, Deger O, Topbas M. Prevalence of prehypertension and hypertension and associated risk factors among Turkish adults: Trabzon Hypertension Study. J Public Health (Oxf) 2009;31:47-58.

15. Prince MJ, Ebrahim S, Acosta D, et al. Hypertension prevalence, awareness, treatment and control among older people in Latin America, India and China: a 10/66 cross-sectional population-based survey. J Hypertens 2012;30:177-87. 